\title{
Proposed changes in CMA governance structure controversial
}

\author{
Early released on Aug. 20, 2008
}

$\mathrm{P}$ roposed changes to the Canadian Medical Association's (CMA's) governance structure have proved controversial among delegates to the association's annual general council in particular, recommendations calling to eliminate the voting rights of some medical organizations and to reduce the size of CMA's core councils.

The recommended changes, which are scheduled to be voted on Aug. 20, 2008 , were hotly debated during information and review sessions Aug. 17, 2008, and Aug. 18, 2008, respectively. Former CMA President Dr. Victor Dirnfeld was particularly outspoken about some changes that he characterized as a "move towards an industrial model of efficiency" that might serve to gag dissent in the association.

And delegates from smaller provinces expressed concern about the proposed move away from divisional towards regional representation on the CMA core councils, which would reduce voting membership from 15 to 8 .

"I fear, as a small province, that the risk is that our voice will be completely lost," said Dr. Lydia Hatcher, a divisional representative from Newfoundland.

The change is of special concern to the Yukon, said Dr. Wayne MacNicol of Whitehorse, Yukon. "The unique perspective of the north and isolated regions will be lost. I don't think all the leadership forums and e-conferences will replace" representation on core councils.

Earlier this year, the CMA board of directors unanimously accepted a package of 25 recommended changes developed after extensive consultation with the membership, and are now asking general council to vote on the package as a whole.

The rationale for the changes is to update the governance structure in accord with current practices; to streamline the operations of the board (membership would be reduced from 34 to 25 ); and to reduce the size of core councils (which would be renamed as committees) to help them respond more promptly and effectively to member concerns and emerging issues.

A motion to accept the entire package will require only a simple majority to pass. If it fails, the recommendations will be voted on individually. (A few bylaw changes will also be necessary and will require a two-thirds majority to pass.)

A key change would see 15 focused medical interest associations - including the Canadian Association of Physicians for the Environment, the Canadian Medical Protective Association and the Federation of Medical Women of Canada - lose their voting rights at general council. These associations would be shifted to associate status, and hold only observer status at the annual meeting.

Under the proposed changes, the Committee on National Medical Organizations - which is now comprised of the focused medical interest groups, as well as the national specialty societies — would be replaced by a specialists' forum.

The focused medical interest groups "do add to the diversity of general council and we want to hear their input," said CMA board member Dr. T.K. Lee.
But there has been concern about the growth in the number and influence of those groups as voting members at general council and hence a concern about the "protection of votes of federated members of the CMA," explained Dr. John Rapin, CMA honorary treasurer and executive committee member.

Some delegates said there was little rationale for the shift to regional membership.

"I have yet to hear a credible reason to go from divisional to regional membership - nimbleness [of response] has never been an issue," said Dr. Guido Van Rosendaal of Calgary, chair of the CMA council on health care and promotion.

However, Dr. Janice Willett of Ontario argued that "it's not the size of the committee that matters. It is getting the process right." She told the review session that she was surprised by the discussion because "it gives me the sense there is not confidence in the board that we elected."

Lee said the advantages of divisional representation on core councils could be implemented through other types of member involvement, including more spots for smaller provinces to go to leadership meetings and opportunities to serve on time-limited task forces established by the board of directors in a revised governance structure. To that end, new monies would be available to bring doctors from provincial and territorial medical associations to the CMA leaders' forum. - Ann Silversides, CMAJ

CMAJ 2009. DOI:10.1503/cmaj.081313 